\title{
南水北调中线水源区浮游植物与水质评价
}

\author{
张乃群 ${ }^{1}$ 杜敏华 ${ }^{1} \quad$ 庞振凌 ${ }^{1}$ 李玉英 ${ }^{1} \quad$ 胡兰群 $^{2}$ \\ （1 南阳师范学院生物系, 河南南阳 473061）（2 南阳市环境保护监测站, 河南南阳 473000）
}

\begin{abstract}
摘 要 通过 2003 年 3 月至 2005 年 8 月对南水北调中线水源区水体浮游植物的调查 结果表明 该水域共有浮游 植物 $8 门 63$ 属 96 种及变种, 其中以硅藻的种类最多, 其次是绿藻和蓝藻。藻类的细胞密度表现出明显的季节变 化, 夏季最高冬季最低。从近 3 年的浮游生物检测结果可知, 整个水源区年平均藻类细胞密度为 $109.33 \times 10^{4} \mathrm{cells}$ $\mathrm{L}^{-1}$ 处于较低的水平, 而且未检出水体重污染指示种, 充分说明南水北调中线水源区富营养化程度较低。运用 Margalef 和 Menkinick 多样性指数对该水域的水质进行评价 数据显示 2003 2005 年该水源区的 $d$ 值和 $\alpha$ 值，各采样 点之间的差异并不显著, 说明各采样点的水质营养状况虽有差异, 但总体水平基本相当。水质评价结果 水体为寡 污型 基本处于中营养状态。通过水生生物资源的调查, 做好水源区的长期生态监测, 可为建立中线水源区长期生 态研究数据信息库及库区生态环境保护政策制定提供理论依据，对保证中线水质质量十分重要。
\end{abstract}

关键词 南水北调中线水源区 浮游植物 生物检测 群落结构 水质评价

\section{INVESTIGATION OF PHYTOPLANKTON AND EVALUATION OF WATER QUALITY IN THE WATER SOURCE AREA OF THE MIDDLE LINE PROJECT FOR TRANSFERRING WATER FROM SOUTH TO NORTH}

\author{
ZHANG Nai-Qun ${ }^{1}$ DU Min-Hua ${ }^{1}$ PANG Zhen-Ling ${ }^{1}$ LI Yu-Ying ${ }^{1}$ and HU Lan-Qun ${ }^{2}$ \\ (1 Department of Life Sciences, Nanyang Teachers' College , Nanyang, Henan 473061 , China) \\ (2 Nanyang Environmental Prevention and Supervision Station, Nanyang , Henan 473000 , China)
}

\begin{abstract}
Background and Aims The water source area of the middle line project for transferring water from south to north is in the interface of Henan, Hubei and Shaanxi Provinces, the largest source of freshwater in Asia. Economic development of the area surrounding the Danjiangkou Reservoir will affect water quality. The objective of this study is to develop methods for monitoring biological resources , including annual changes of plankton in the reservoir , in order to provide a scientific base for sustainable exploitation , protection of biological resources , regulations for water resource protection , and establishment of a database for long-term ecological research on the middle line project.
\end{abstract}

Methods Water samples were collected using standard methods at three points of Qushou, Kuxin and Dashiqiao from March 2003 to August 2005 , for biological , physical , and chemical analyses. Qualitative samples were collected using 25 phytoplankton networks, and taxa were identified by ordinary microscopes. Quantitative samples were collected using bottles and were fixed in Lugol's medium. Samples were condensed and counted in the laboratory under light microscopy with a phytoplankton counter frame. Algal diversity was calculated using Margalef and Menkinick diversity indices.

Key Results Samples contained 96 species and varieties , 63 genera , and 8 divisions of phytoplankton ; diatoms were the most important component, followed by green algae and blue green algae (cyanobacteria). Cell densities exhibited seasonal changes, with maximum values in summer and minimum values in winter. Investigation of phytoplankton from three recent years showed an average annual density of algae of $109.33 \times 10^{4}$ cells $\mathrm{L}^{-1}$ at low water level, and no pollution of indicator species was detected in the water sources. Application of diversity indices to assessment of water quality showed the $d, \alpha$ value , and differences among the different sample sites were small. There were only small differences in water quality nutrition status.

Conclusions Water quality indicated mesotrophy and middle nutrition status. This study provides a scientific base for long-term ecological research on biological resources and for policy development for ecological environmental protection. It will have an important effect on the water quality on the middle line project.

Key words Water source area of the middle line project of transferring water from south to north , Phytoplankton , Biological monitoring, Species community, Water quality assessment 
南水北调工程包括西线、中线和东线工程, 是我 国水资源调整的一项战略性基础工程。南水北调中 线水源区位于豫、鄂、陕三省交界处的丹江口水库， 是亚洲最大的人工淡水湖，流域面积 $9.5 \times 10^{4} \mathrm{~km}^{2}$, 总库容量达 408.5 亿 $\mathrm{t}$ (徐黎和李光华, 2003)。取水 源头在河南省南阳市境内, 界于 $111^{\circ} 01^{\prime} \sim 111^{\circ} 18^{\prime}$ E、32 $55^{\prime} \sim 33^{\circ} 48^{\prime} \mathrm{N}$ 之间，处于北亚热带向暖温带的 过渡带。区域内森林覆盖率平均为 $53.68 \%$, 平均 年降雨量为 $808 \mathrm{~mm}$ 。

丹江口水库的入库河流水量大, 水质较好。但 随着库区周围地区经济的不断发展, 由于自然及人 为因素使入库干、支流水质发生变化, 必将影响丹江 口水库的水质(徐黎和李光华,2003)。水环境决定 了生物种群或群落结构特征, 生物个体、种群或群落 的变化, 同样可以客观反映出水体质量的变化规律 (邓义祥和张爱军, 1998)。据此, 为探索中线水源区 生物监测途径, 本研究从 2003 年开始逐年进行浮游 生物监测 希望能为可持续开发和保护水生生物资 源及制定水源保护措施提供科学依据, 为建立中线 水源区长期生态研究数据信息库打下基础。

\section{1 研究方法}

\section{1 采样点布设}

国家环境监测总站授权南阳市环境保护监测站 监测南水北调中线水源区而设置的 S1、S2 和 S3 依 次为渠首 (陶岔) 、库心 (小太平洋) 和大石桥 (丹江口 入库上游) 3 个水质监测点。

\section{2 样品采集与鉴定}

\subsection{1 水样采集}

2003 年 3 月至 2005 年 8 月, 分季节在渠首、库 心、大石桥 3 个点, 按水样采集标准采集生物检测样 和理化检测样。定性样品用 25 号浮游植物采集网 采集, 定量样品用采水器分层采取 $1000 \mathrm{ml}$ 现场加 鲁哥氏液固定。实验室浓缩样品并进行种类鉴定 (金相灿和屠清瑛,1990;水和废水监测分析方法编 委会, 2002 ; 辛晓云, 2003 )。

\subsection{2 浮游植物的鉴定和细胞计数}

定性样品 取定性水样在普通显微镜下鉴定 将 浮游植物鉴定到种或属 ( Foott, 1980; 韩茂森, 1980; 胡鸿钧等, 1979; Smith, 1950; 饶钦止, 1988; 厦门水产 学院水生物教研组 ,1980)。

定量样品 将已固定的水样按常规方法沉淀、去 除上清液、定容至 $30 \mathrm{ml}$ 用浮游植物计数框在光学 显微镜下作定量计数。计数时充分摇匀后取 $0.1 \mathrm{ml}$
浓缩液于 $0.1 \mathrm{ml}$ 计数框中, 在 $10 \times 40$ 倍显微镜下观 察, 计数 100 个视野, 然后换算成每升水样中藻类的 细胞个数(王朝晖等 2000 ; 況琪军等 2004)。

\subsection{3 多样性指数的计算}

藻类多样性指数分别运用 Margalef 多样性指数 计算公式 $d=(S-1) / \ln N$ 和 Menkinick 多样性指数 计算公式 $\alpha=(S / \sqrt{\mathrm{N}}) \cdot 1000$ 进行计算 (Margalef, 1958 ;James \& Jerrold ,1977)。式中 : $d$ 和 $\alpha$ 均表示多 样性指数, $S$ 为种类数, $N$ 为细胞密度。

\subsection{4 水质的理化检测}

渠首 (陶岔) 水质的理化检测由在渠首设的自动 监测仪测定 (同时进行人工平行样测定)。其它两个 点的水温 $(T)$ 、溶解氧 $(D O) 、 \mathrm{pH}$ 值 $(\mathrm{pH})$ 、电导率 $(E C)$ 由便携式仪器测定。透明度采用塞氏盘法测 定。总磷 $(T P)$ 、总氮 $(T N)$ 、生化需氧量 $(B O D)$ 、化 学需氧量 $(C O D)$ 参照文献 (水和废水监测分析方法 编委会 ,2002)测定。

\section{2 结果与分析}

\section{1 水源区浮游植物检测结果}

\subsection{1 浮游植物种类组成}

3 个采样点共检测到藻类 8 门 63 属 96 种及变 种, 其中硅藻门 22 属 43 种及变种, 绿藻门 23 属 32 种及变种; 蓝藻门 10 属 11 种; 㳌藻门 3 属 3 种;裸 藻门 1 属 3 种, 黄藻门 2 属 2 种, 金藻门 1 属 1 种和 隐藻门 1 属 1 种(图 1 )。

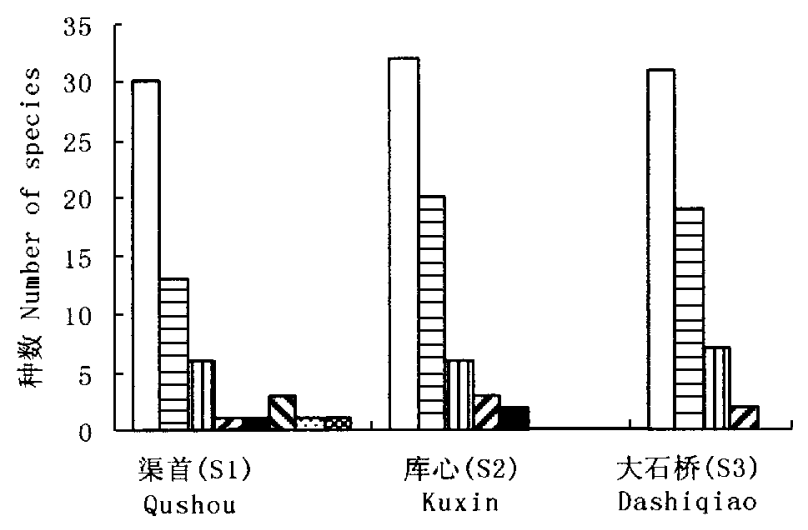

采样点 Sampling stations

口硅藻门Bac 日绿藻门Ch1 四蓝藻门Cya D黄藻门Xan

a裸藻门Eug $\mathbf{g}$ 甲藻门Din日金藻门Chr 因隐藻门Cry

\section{图 1 南水北调水源区浮游植物种类组成}

Fig. 1 Composition of phytoplankton species in water source area of the middle line project of transferring water from south to north

Bac : Bacillariophyta Chl : Chlorophyta Cya : Cyanophyta Xan : Xanthophyta Eug : Euglenophyta Din : Dinophyta Chr : Chrysophyta Cry : Cryptophyta 
从各采样点浮游植物种类组成来看, 硅藻的种 类最多, 其比例在各样点均为 $60 \%$ 左右, 其次是绿 藻, 裸藻、金藻和隐藻仅在渠首发现, 甲藻和黄藻虽 在 3 个采样点都检测到, 但这几门藻类数量较少, 其 种数之和仅占全部种数的 $10.4 \%$ 。而且各采样点 均未发现极为单一的优势群落 种间差别不太明显。 从数量和出现频度来看, 硅藻门的缢缩曲壳藻 (Achnanthes coarctata)、同心扭曲小环藻 (Cyclotella comta)、几种桥穹藻 (Cymbella sp.) 、肋缝硅藻 (Frustulia sp.)、狭形颗粒直链藻 (Melosira granulata var. angustissima) 绿藻门的格孔单突盘星藻 (Pediastrum simplex var. clathratum)、棘球藻 (Echinosphaerilla limnetica) 蓝藻门的细小平裂藻 (Merismopedia tenuissi$m a$ )、小型色球藻 (Chroococcus minor) 等, 在数量上占 一定比例, 而且在各采样点均有出现, 是较为主要的 种类。

\subsection{2 浮游植物的细胞密度}

浮游植物的细胞密度是水生生态系统功能和水 质评价的重要参数之一, 图 2 显示了 2003 年 3 月至 2005 年 8 月期间采样点各季节的平均值, 最低为
$54.13 \times 10^{4}$ cells $\mathrm{L}^{-1}$ 最高为 $184.53 \times 10^{4}$ cells $\mathrm{L}^{-1}$ 。 由图 2 可以看出同一采样点浮游植物的细胞密度季 节差异明显。各采样点藻类的细胞数量均在夏季出 现高峰 秋季冬季出现最低值, 秋季略低于夏季, 而 春季稍高于冬季, 这种情况与况琪军等 (2004) 的结 果一致。表 1 显示整个水源区各采样点年平均藻类 细胞密度为 $109.33 \times 10^{4}$ cells $\mathrm{L}^{-1}$ 。

\section{2 水源区理化检测指标}

3 个检测点同步理化检测结果见表 2。根据国 家环保总局和国家质量监督检验检疫总局 2002 年 4 月 28 日发布的地表水环境质量标准 GB38382002 " 总氮 (湖、库, 以 $\mathrm{N}$ 计) 标准为: $\mathrm{I}$ 类水质 $\leqslant 0.2$ ， II 类水质 $\leqslant 0.5$,III 类水质 $\leqslant 1.0$ 。从理化指标看水 源区水质，除 TN 指标属于 III 类水质标准外，其它监 测指标均符合 I 类水质标准。

\section{3 水源区水质初步评价}

藻类的污染指示种是水质生物学评价的重要参 数(辛晓云,2003;王朝晖等,2000;況琪军等,2004)。 参照 Foott (1980) 有关指示性藻类的观点, 将鉴定所 得污染指示种列于表 1 。从表 1 可知，中线水源区

表 1 南水北调中线水源区藻类年均细胞密度与种类多样性指数

Table 1 Annual mean cells and species diversity of algae in water source area of the middle line project of transferring water from south to north

\begin{tabular}{|c|c|c|c|c|c|c|c|c|}
\hline \multirow{3}{*}{$\begin{array}{c}\text { 采样点 } \\
\text { Sampling } \\
\text { sites }\end{array}$} & \multirow{3}{*}{$\begin{array}{c}\text { 种数 } \\
\text { Numbet of species }\end{array}$} & \multirow{3}{*}{$\begin{array}{c}\text { 细胞密度 } \\
\text { Cell density } \\
\left(\times 10^{4} \text { cells L }{ }^{-1}\right)\end{array}$} & \multicolumn{4}{|c|}{ 污染指示种 Instructive species of pollution } & \multirow{2}{*}{\multicolumn{2}{|c|}{$\begin{array}{l}\text { 多样性指数 } \\
\text { Index values }\end{array}$}} \\
\hline & & & \multirow{2}{*}{$\begin{array}{c}\beta \text {-中污 } \\
\beta \text {-ms }\end{array}$} & \multirow{2}{*}{$\begin{array}{c}\alpha-\beta-\text {-中污 } \\
\alpha-\beta-\mathrm{ms}\end{array}$} & \multirow{2}{*}{$\begin{array}{c}\alpha \text {-中污 } \\
\alpha \text {-ms }\end{array}$} & \multirow{2}{*}{$\begin{array}{c}\text { 寡污 } \\
\text { os }\end{array}$} & & \\
\hline & & & & & & & $d$ & $\alpha$ \\
\hline 渠首 Qushou (S1) & 56 & 126.61 & 17 & 3 & 2 & 12 & 3.9142 & 49.7684 \\
\hline 库心 Kuxin (S2) & 63 & 103.73 & 12 & 1 & 0 & 8 & 4.4758 & 61.8569 \\
\hline 大石桥 Dashiqiao (S3) & 59 & 97.64 & 15 & 3 & 1 & 8 & 4.2054 & 59.7088 \\
\hline
\end{tabular}

评价标准 Evaluated standards (Margalef , 1958 ; James \& Jerrold ,1977) : $d>3$ 轻或无污染 Oligosaprobic or cleanness $d=1 \sim 3$ :中污染 Mesosaprobic $d=0 \sim 1$ 重污染 Hypersaprobic $\quad \alpha=5$ 清洁 Cleanness $\quad \alpha>4$ 寡污 Oligosaprobic $\quad \alpha>3$; $\beta$-中污 $\beta$-mesosaprobic $\quad \alpha<3$ : $\alpha$-中污 $\alpha$-mesosaprobic
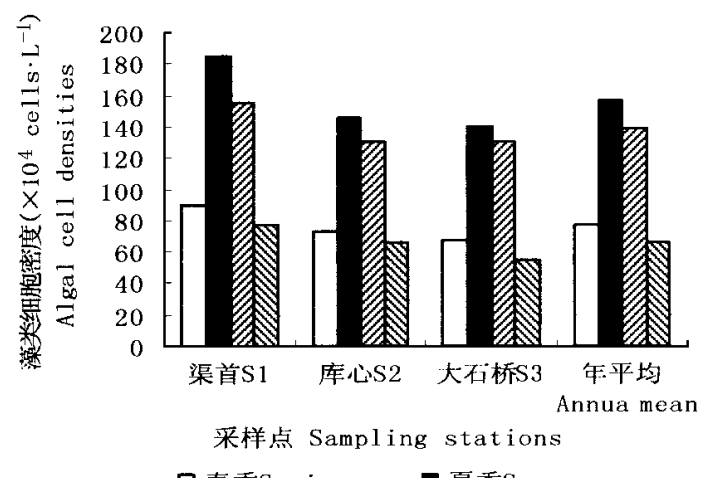

$\begin{array}{ll}\text { 口春季Spring } & \text { 夏季Summer } \\ \text { 田秋季Autumn } & \text { 图季Winter }\end{array}$

图 2 南水北调中线水源区藻类细胞密度季节变化

Fig.2 Seasonal changes of algal cell densities in water source area of the middle line project of transferring water from south to north

S1 ,S2 ,S3 : See Table 1
未检出水体重污染指示种 $(\rho s)$, $\beta$-中污 ( $\beta-m s)$ 种类有 22 种, $\alpha$ - $\beta$-中污 $(\alpha-\beta-m s)$ 种类有 4 种, $\alpha$-中污 $(\alpha-m s)$ 种 类有 3 种 寡污 $(\mathrm{os})$ 种类有 18 种。虽然检测出污染 指示种达 47 种, 但其中有 34 种出现在渠首, 占检出 污染指示种种数的 $72.34 \%$ 。渠首采样点位于渠闸 内侧，目前尚未启动调水系统，其浮游植物种类情况 与其它两个检测点有较大差异。因此, 目前对水源 区水质的评价应侧重于库心 (S2) 和大石桥 (S3) 这两 个检测点。

种类多样性指数是常用的水质评价指标, 主要 依据藻类细胞密度和种群结构的变化评价水体的污 染程度, 通常情况下指数值越大, 水质越净 (况琪军 等 2004)。表 1 列举了应用 Margalef 多样性指数和 Menkinick 多样性指数计算公式, 对各采样点浮游植 
物的种类多样性进行计算的结果，数据显示 2003 2005 年该水域的 $d$ 和 $\alpha$ 值, 各采样点之间的差异并 不显著, 说明各采样点的水质营养状况虽有差异, 但 总体水平基本相当。根据评价标准，该水体水质应 为寡污型。
根据郭沛涌等 (1997)和詹玉涛等 (1991)利用指 示性浮游植物群落划分的污染等级, 分析表 1 和图 1 ,在南水北调中线水源区浮游植物以硅藻为优势类 群 种数在 3 个采样点均在 $60 \%$ 左右。以上分析说 明南水北调中线水源区水体基本处于中营养状态。

表 2 南水北调中线水源区理化检测结果

Table 2 The result of physicochemical monitoring on water source area of the middle line project of transferring water from south to north

\begin{tabular}{|c|c|c|c|c|c|c|c|c|c|c|}
\hline $\begin{array}{c}\text { 采样点 } \\
\text { Sampling point }\end{array}$ & $\begin{array}{c}\text { 采样时间 } \\
\text { Sampling time }\end{array}$ & $\begin{array}{c}T \\
\left({ }^{\circ} \mathrm{C}\right)\end{array}$ & $\mathrm{pH}$ & $\begin{array}{c}D O \\
\left(\mathrm{mg} \mathrm{L} \mathrm{L}^{-1}\right)\end{array}$ & $\begin{array}{c}\text { 透明度 } \\
\text { Transparency }(\mathrm{m})\end{array}$ & $\begin{array}{c}E C \\
\left(\mu \mathrm{sm}^{-1}\right)\end{array}$ & $\begin{array}{c}T N \\
\left(\mathrm{mg} \mathrm{L} \mathrm{L}^{-1}\right)\end{array}$ & $\begin{array}{c}T P \\
\left(\mathrm{mg} \mathrm{L} \mathrm{L}^{-1}\right)\end{array}$ & $\begin{array}{c}C O D \\
\left(\mathrm{mg} \mathrm{L}^{-1}\right)\end{array}$ & $\begin{array}{c}B O D \\
\left(\mathrm{mg} \mathrm{L}^{-1}\right)\end{array}$ \\
\hline \multirow[t]{4}{*}{ S1 } & 春季 Spring & 10.2 & 6.91 & 8.37 & 1.40 & 27.8 & 0.835 & 0 & $<10$ & $<2$ \\
\hline & 夏季 Summer & 23.0 & 7.32 & 8.15 & 1.50 & 35.8 & 0.827 & 0 & $<10$ & $<2$ \\
\hline & 秋季 Autumn & 27.4 & 7.50 & 7.67 & 0.90 & 25.6 & 0.717 & 0.005 & 12.6 & 2.34 \\
\hline & 冬季 Winter & 18.6 & 8.33 & 8.12 & 2.50 & 21.0 & 0.709 & 0.005 & 17.9 & 4.1 \\
\hline \multirow[t]{4}{*}{ S2 } & 春季 Spring & 10.0 & 6.94 & 8.74 & 3.77 & 31.3 & 0.714 & 0 & $<10$ & $<2$ \\
\hline & 夏季 Summer & 22.0 & 7.32 & 8.49 & 2.10 & 31.4 & 0.726 & 0 & $<10$ & $<2$ \\
\hline & 秋季 Autumn & 27.0 & 8.47 & 7.02 & 2.65 & 25.2 & 0.637 & 0.005 & 11.0 & 2.27 \\
\hline & 冬季 Winter & 19.6 & 8.29 & 8.24 & 3.00 & 20.0 & 0.614 & 0.005 & 10.0 & 2.00 \\
\hline \multirow[t]{4}{*}{ S3 } & 春季 Spring & 17.0 & 8.35 & 7.06 & - & - & - & - & 20.0 & 3.99 \\
\hline & 夏季 Summer & 22.0 & 7.70 & 7.85 & - & - & - & - & 18.0 & 3.24 \\
\hline & 秋季 Autumn & 21.0 & 8.34 & 6.78 & - & - & - & - & 15.4 & 3.54 \\
\hline & 冬季 Winter & 18.5 & 7.53 & 7.69 & - & - & - & - & 16.4 & 4.0 \\
\hline
\end{tabular}

$\mathrm{S} 1 \mathrm{~S} 2 \mathrm{~S} 3$ :同表 1 See Table $1 \quad T$ 水温 Water temperature $\quad D O$ 溶解氧 Dissolved oxygen $E C$ 电导率 Electric conductivity $T N$ :总氮 Total nitrogen $T P$ 搃磷 Total phosphorus $C O D$ :化学需氧量 Chemical oxygen demand $B O D$ :生化需氧量 Biochemical oxygen demand

\section{3 讨 论}

在水环境中，许多化合物和潜在的污染物质所 产生的有害生物效应浓度往往是现有的分析手段无 法测出的。它们常以混合状态存在于水体中，且相 互作用产生综合污染。当不同污染因子同时作用于 生物时,又可产生相加、相乘或拮抗作用,使生物受 害程度较单因子作用加重或减轻。因此,必须将污 染物、水相、生物诸因素综合在一起，才能提供有效 的水环境管理信息。从生态学观点出发, 生物与环 境的统一是生物与环境相互作用的结果, 水环境决 定了生物种群或群落结构特征,反之, 生物的个体、 种群或群落的变化, 可以客观反映出水体质量的变 化规律。依据上述生态学原理, 在生态调查基础上 从物理学、化学、生物学角度综合评价南水北调中线 水源水质才是科学的，且通过水生生物资源的调查， 将为可持续开发和保护水产生物资源及制定水源保 护措施提供科学依据。

水体的富营养化程度与气候、生物、环境条件和 水库调度方式等密切相关。从近 3 年的浮游生物检 测结果可知, 整个水源区年平均藻类细胞密度为 $109.33 \times 10^{4}$ cells $\mathrm{L}^{-1}$, 处于较低的水平, 密云水库 2001 年浮游植物细胞密度已达 $376.20 \times 10^{4}$ cells $L^{-1}$ (刘霞等，2003）,而且未检出水体重污染指 示种，充分说明南水北调中线水源区富营养化程度 较低。但是要确保京、津等供水区居民健康、工农业 生产和库区经济持续发展, 对丹江口水库各干流和 建设中的调水渠道进行流域生态工程规划已是当务 之急，其中加快主、干流及库区生态林、生态农业、生 态工业的建设，对将建成的渠道进行生态景观廊道 布局设计是关键; 另外水源地豫、鄂、陕 3 省及沿渠 省市应协调共管，并建立一套完善的水污染防治体 系，以控制污染源为主的营养化防治措施，充分发挥 水利工程调度优势，以便有效防治水质污染和水体 富营养化的发生 ,保证中线水域生态系统持续健康， 确保调水的水质，以实现社会、经济、生态协调可持 续发展。

做好水源区的长期生态监测，可为建立中线水 源区长期生态研究数据信息库及库区生态环境保护 政策制定提供理论依据，对保证中线水质质量有着 十分重要和深远的意义。有关中线水源区生物种群 动态变化及水库营养状态还有待深入研究。

\section{参 考 文 献}

Deng YX(邓义祥), Zhang AJ(张爱军) (1998). The use of algae in water contamination monitor. Resource Development \& Market (资源开发与市场) , 14, 197-198. (in Chinese with English 
abstract)

Foott B (translated by Luo DA (罗迪安)) (1980). Phycology (藻 类学). Shanghai Science and Technology Press, Shanghai. (in Chinese)

Guo PY(郭沛涌), Lin YZ(林育真), Li YX(李玉仙) (1997). Study on phytoplankton and evaluation of water quality in Dongping Lake. Transactions of Oceanlogy and Limnology (海洋湖沼 通报)，19, 37-42. (in Chinese with English abstract)

Han MS (韩茂森) (1980). The Atlas of Freshwater Plankton (淡水 浮游生物图谱). China Agriculture Press, Beijing. 1-89. (in Chinese)

Hu HJ (胡鸿钧), Li YY (李尧英), Wei YX(魏印心) (1980). Chinese Freshwater Algae (中国淡水藻类). Shanghai Science and Technology Press, Shanghai. (in Chinese)

James EB, Jerrold HZ (1977). Field and Laboratory Methods for General Ecology. American Public Health Association, Washington DC, $136-145$.

Jin XC(金相灿)，Tu QY(屠清瑛)（1990）. The Standard Methods in Lake Eutrophication Investigation (湖泊富营养化调查规 范) 2nd edn. China Environmental Science Press, Beijing, 143 - 302. (in Chinese)

Kuang QJ(况琪军), Hu ZY(胡征宇), Zhou GJ(周广杰), Ye L (叶麟), Cai QH(蔡庆华) (2004). Investigation on phytoplankton in Xiangxi River watershed and the evaluation of its water quality. Journal of Wuhan Botanical Research (武汉植物学 研究) , 22, 507-513. (in Chinese with English abstract)

Marglef DR (1958). Information theory in ecology. General Systems, 3, 36-71.

Rao QZ(饶钦止) (1988). Foira Algarum Sinicarum Aquae Dulcis, Tomus. I. Zygnemataceae (中国淡水藻志第一卷, 双星藻 科). Science Press, Beijing. (in Chinese)

Smith GM(1950). The Fresh-Water Algae of the United States 2nd edn. McGraw-Hill Book Co., New York.

Teaching and Research Section of Aquatic Species of Fisheries Col- lege of Xiamen (厦门水产学院水生物教研组) (1980). The Common Freshwater Algae (淡水习见藻类). China Agriculture Press, Beijing. (in Chinese)

The Editorial Committee of Water and Exhausted Water Monitoring Analysis Method(水和废水监测分析方法编委会) (2002). Water and Exhausted Water Monitoring Analysis Method (水和废 水监测分析方法) 4th edn. China Environmental Science Press, Beijing. (in Chinese)

Wang $\mathrm{ZH}$ (王朝晖)，Chen JF( 陈菊芳)，Qi S(杞桑)，Jiang TJ (江天久), Qi YZ(齐雨藻) (2000). Studies on quantitative distribution and species composition of phytoplankton in star lake and the evaluation of its trophic status. Journal of Wuhan Botanical Research (武汉植物学研究)，18, 405-411. (in Chinese with English abstract)

Xin XY (辛晓云) (2003). Assessment of water pollution using population structure of floating diatom in Nanwan Resservoir in Henan. Chinese Journal of Ecology (生态学杂志), 22, 125 126. (in Chinese with English abstract)

Xu L(徐黎), Li GH (李光华) (2003). Ecological environment comprehensive treatment in the Mid-Line Project of South to North Water Diversion. Journal of North China Institute of Water Conservancy and Hydroelectric Power (华北水利水电学院学报), 24(2), 74-77. (in Chinese with English abstract)

Zhan YT (詹玉涛), Yang CS (杨昌述), Fan ZN (范正年) (1991). Study on interrelation between distribution of phytoplankton and water pollution in Fuqi River. China Environmental Science (中国环境科学) , 11, 29-33. (in Chinese with English abstract)

Liu X(刘霞), Du GS(杜桂森), Zhang H(张会), Hua ZL(华振 玲), Liu J(刘静) (2003). Phytoplankton and nutrient degree of water body in Miyun Reservoir. Research of Environmental Sciences (环境科学研究) , 16, $27-29$. (in Chinese with English abstract) 